\title{
MONITORING LEAFROLLERS (LEPIDOPTERA: TORTRICIDAE) IN VINEYARDS
}

\author{
P.L. LO and J.T.S. WALKER \\ HortResearch, Hawke's Bay Research Centre, Private Bag 1401, \\ Havelock North
}

Corresponding author: plo@hortresearch.co.nz

\begin{abstract}
Leafroller larvae, especially Epiphyas postvittana, damage grape bunches, and more importantly promote spread of the disease botrytis (Botrytis cinerea). Three methods of monitoring leafrollers were compared on 10 Hawke's Bay vineyard blocks. The methods were timed searches of leaves for larvae, inspection of bunches for larvae, and pheromone trapping of adult males. Seasonal changes in leafroller abundance were similar on all vineyards. Usually few larvae were found until February, but infestations increased greatly between then and March. In other respects, leafroller infestations were variable between and sometimes within blocks. None of the monitoring methods was completely successful. The most useful method was bunch inspection, primarily because of the close correlation between bunch infestations in January and at harvest. However, this method is relatively laborious and did not give enough warning to enable use of some insecticides. Leafroller infestations on leaves in all months and pheromone trap data were poor predictors of harvest bunch damage.

Keywords: Epiphyas postvittana, lightbrown apple moth, leafroller, spray threshold, grape.
\end{abstract}

\section{INTRODUCTION}

The lightbrown apple moth, Epiphyas postvittana (Walker) (LBAM) (Lepidoptera: Tortricidae), is a key pest of grapevines in New Zealand and Australia (Baker et al. 1994). Feeding by leafroller larvae on flowers, berries and stalks causes a direct reduction in yield. The larvae can also vector Botrytis cinerea spores and thereby increase both the incidence of infected bunches and the severity of botrytis within bunches (Bailey et al. 1997). Bunches artificially infested with LBAM larvae were on average up to $12 \%$ lighter than uninfested bunches at harvest, through a combination of feeding damage and higher incidence of botrytis (Lo \& Murrell 2000). Overall the indirect losses incurred from disease outweighed those from feeding damage (Buchanan 1977; Lo \& Murrell 2000).

The New Zealand winegrape industry has developed a best practice environmental grape production programme called Sustainable Winegrowing New Zealand (SWNZ) (Charles 2005). Priority in this programme is given to biological and cultural control practices, with pesticides applied only when necessary. Pest populations and disease levels are monitored and decisions to use control measures are based on pre-determined thresholds. Selective pesticides compatible with biological control are used where possible.

Monitoring methods and spray thresholds for LBAM have been developed for Australian vineyards (Baker et al. 1994; Shanks et al. 2000), but equivalent research has not been conducted in New Zealand. The objective of the current research was to evaluate the suitability of three methods for monitoring larval and adult leafrollers and if possible estimate spray thresholds. To be useful a monitoring method needs to 
(a) be an accurate predictor of likely crop damage levels, (b) give sufficient warning that growers can take preventative action, and (c) be cost effective and efficient to conduct over large areas.

\section{METHODS}

The trial was conducted on 10 blocks at four Hawke's Bay vineyards from December 1997 to April 1998. Two vineyards (A\&B) had one block of Chardonnay and one of Merlot, vineyard D had two blocks of each variety and at vineyard C Cabernet Sauvignon was substituted for Chardonnay. The blocks in each vineyard were within $150 \mathrm{~m}$ of each other and similar with regard to the surrounding vegetation and land use. Insecticides were not applied to the trial blocks during the study except for one application against leafrollers of Bacillus thuringiensis (Bt) on 17 January to both blocks at vineyard A. Bt loses its efficacy within a few days of application so would have only briefly affected leafroller populations.

The monitoring methods tested were timed searches of leaves and examination of fruit bunches to measure the abundance of larvae on vines, and pheromone traps for determining the flight activity of adult males.

\section{Vine inspections}

Leaves and bunches were inspected for immature leafrollers monthly from December to March. An extra leaf sample was conducted in April after harvest. Preliminary sampling found monitoring for eggs or larvae earlier than December was impractical because of low numbers of leafroller. One row in the centre of each block was divided into six equal sectors and one 5-minute search of foliage covering 15-20 m was made in each sector (30 minutes per block per visit). Leaves were examined for leafroller-folded or chewed leaves and the characteristic white webbing. Leafroller-damaged leaves were collected for later examination. Leaf searches took 40-50 minutes per person per block, including the time spent walking between search areas.

Two hundred bunches in each of two central rows per block were examined across six evenly spread sectors as above. Bunches were selected randomly within each sector, and records made of those with larvae or pupae, including parasitised ones, and leafroller damage (webbing, chewed berries and stalks, and collapsed groups of berries). All immature leafrollers found during leaf and bunch searches were collected and reared through to adult to determine their species. Bunches with botrytis were noted and whether or not there were immature leafrollers or leafroller damage in the same bunch. Initially it took about 60 minutes to examine 400 bunches. Later this increased to around 90 minutes because the larger berries made it harder to see inside bunches and more time was spent collecting larvae.

\section{Pheromone trapping}

Adult male LBAM were monitored weekly from December 1997 to March 1998 using Desire $^{\circledR}$ 'Delta' pheromone traps. Two traps, separated by at least $80 \mathrm{~m}$, were located in the centre of each block, except two blocks at Vineyard D which were not trapped. Trap sticky bases and pheromone caps were changed every 3 and 6 weeks respectively.

\section{Data analysis}

Leaf and bunch infestation data were analysed by two-way ANOVA of log $(x+1)$ transformed data. Infestations on leaves and bunches during the season were correlated with the infestation of bunches just before harvest (March). Pheromone trap data of the highest, average and cumulative catches each month were correlated against the abundance of leafrollers on bunches at harvest. Chi-square tests were conducted to determine if infestation levels were evenly distributed throughout the six sectors in each block. 


\section{RESULTS}

Leafroller infestations were similar between grape varieties for both leaves $(\mathrm{P}=0.680)$ and bunches $(\mathrm{P}=0.717)$ so data were combined. Levels of infestation varied widely between vineyards on leaves $(\mathrm{P}=0.020)$ and bunches $(\mathrm{P}=0.003)$. Total numbers of leafrollers found per block ranged from 23-100 on leaves and 10-122 on bunches, and the percentage of bunches infested at harvest was $2-18 \%$. In most blocks, leafroller infestations were evenly distributed throughout the six sectors but on 3/10 blocks for leaves and 4/10 for bunches, infestations were higher at one or both ends of the block. Of the 348 larvae reared 97\% comprised LBAM and 3\% native leafroller species.

All 10 blocks had a similar seasonal pattern of leafroller infestation so the data were combined (Fig.1). Few leafrollers were found on leaves or bunches in December, but the three blocks with the highest bunch infestations at harvest had over $1 \%$ of bunches infested by January. Other blocks had very few infested bunches in February and these eventually had the least damage. Leafrollers were not abundant on leaves in any block until February.

The best predictor of the levels of leafroller infestation on bunches at harvest was bunch examinations (Table 1, Fig. 2). There was a close correlation between infestations at harvest (March) with those in January and February, but not December. The regression equation in Figure $2(y=5.0 x+5.7)$ indicated that for every $1 \%$ increase in bunch infestation in January, a 5\% increase could be expected by March. For monitoring it is simpler to record the number of infested or damaged bunches than to count actual numbers of larvae or pupae. These data had a similarly close correlation $(\mathrm{r}=0.942, \mathrm{y}=4.3 \mathrm{x}+2.1)$ as that for actual numbers. The number of leafrollers on leaves in all months, and pheromone trap data were poor predictors of harvest bunch damage, with non significant correlations (Table 1). Trap catches fluctuated depending on how recently the sticky base had been changed. Correlations of mean monthly catches are not shown but were similar to those for the highest catch.

TABLE 1: Correlations (r) between leafroller bunch infestations in March 1998 with the abundance recorded by three monitoring methods on 10 Hawke's Bay vineyard blocks, December 1997-February 1998.

\begin{tabular}{llrr}
\hline Method & Month & \multicolumn{1}{c}{$\mathrm{r}$} & \multicolumn{1}{c}{$\mathrm{P}$} \\
\hline Bunches & December & 0.018 & 0.961 \\
(no./400 bunches) & January & 0.975 & $<0.001$ \\
& February & 0.833 & 0.003 \\
Leaves & December & 0.186 & 0.608 \\
(no./30 minutes) & January & 0.261 & 0.467 \\
& February & 0.176 & 0.627 \\
Trap catches & December & 0.456 & 0.256 \\
(highest/month) & January & -0.448 & 0.265 \\
& February & 0.474 & 0.235 \\
Trap catches & December & 0.420 & 0.301 \\
(cumulative) & January & 0.022 & 0.958 \\
& February & 0.324 & 0.434 \\
\hline
\end{tabular}

The 1997-98 season was exceptionally dry and the incidence of botrytis just before harvest was low (0-6\% of bunches infected per block). Half of the bunches $(n=75)$ with botrytis had evidence that leafrollers were or had been present. At harvest the abundance of leafrollers in bunches was correlated with the incidence of botrytis $(\mathrm{r}=0.696, \mathrm{P}=0.025)$. 


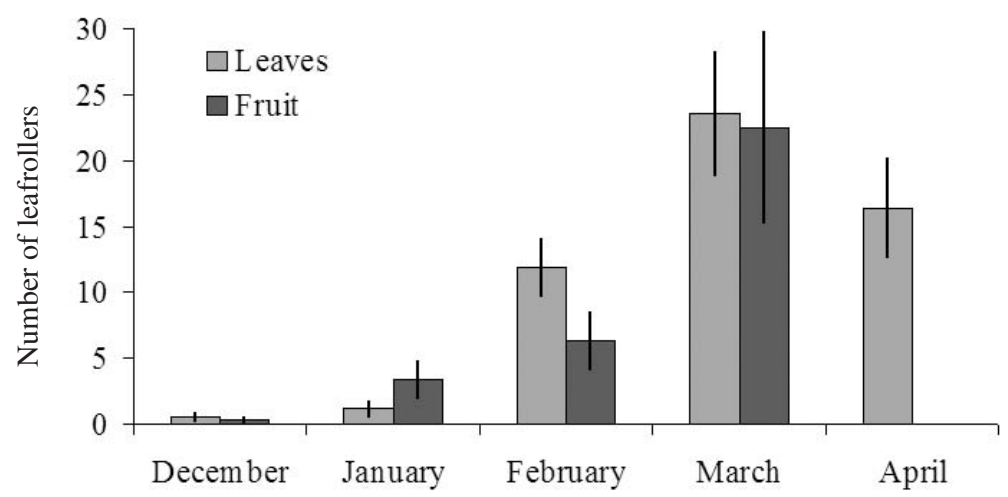

FIGURE 1: Mean $( \pm$ SEM) number of leafrollers found in 30-minute searches on leaves or on 400 bunches per block in 10 Hawke's Bay vineyard blocks, December 1997-March (bunches) or April (leaves) 1998.

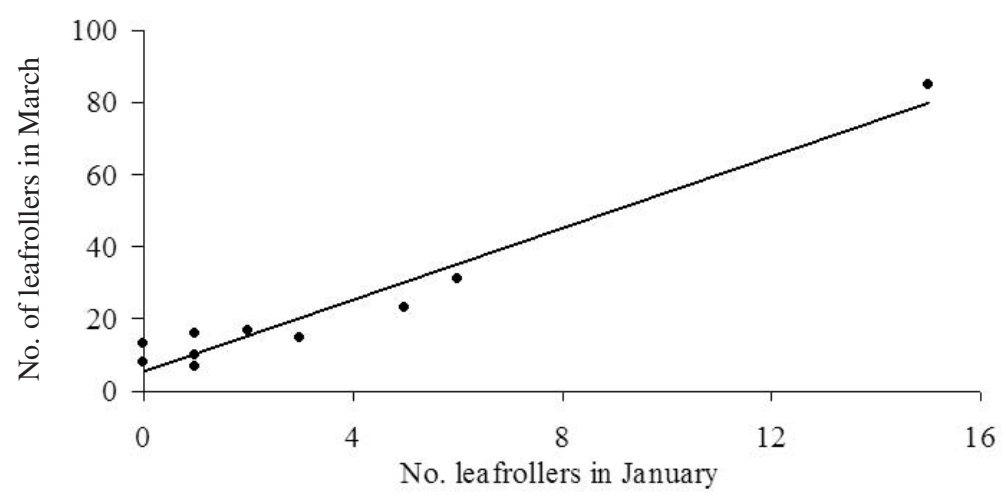

FIGURE 2: Regression between the total number of leafrollers found on bunches in January and in March 1998 on 10 Hawke's Bay vineyard blocks.

\section{DISCUSSION}

A feature of the leafroller infestations in this study was the variability between and within blocks. While it was not surprising that infestations varied widely between vineyards, there were also some differences between blocks on the same vineyard, even though Chardonnay and Merlot blocks were similar overall. Infestations where larvae were evenly distributed throughout the six sectors appeared to originate largely from resident populations. In contrast, blocks with more larvae at one or both ends may have faced greater pressure from immigrating moths. These differences mean that whole vineyards need to be surveyed until experience determines where most damage occurs. The variability of leafroller infestations within blocks means that reducing the sample size risks losing sampling precision.

None of the three monitoring methods completely fulfilled all of the criteria required to set a practical spray threshold. The best method was bunch inspection, which enabled infestation of bunches at harvest in March or April to be accurately predicted in January. 
A threshold of $>3 \%$ of bunches infested in January is suggested, which should prevent damage at harvest from exceeding $15 \%$. January coincides with bunch closure, which is the latest time to get good penetration of sprays into bunches. However, this timing is too late for products with long withholding periods, such as tebufenozide. Tebufenozide is an important SWNZ-compatible leafroller insecticide that must be applied before December, when too few leafrollers are infesting bunches to set a reliable threshold. Bunch examination is a simple method that requires little skill from scouts other than being thorough. It could be combined with monitoring for diseases, but this takes longer and it becomes difficult to do both tasks accurately. The abundance of leafrollers was underestimated when scouts assessed bunches simultaneously for pests and disease (P.L. Lo, unpubl. data).

Because leafrollers tend to infest leaves before bunches, it was hoped that searches of foliage early in the season would be a reliable predictor of harvest damage. While leaf searches usually found more leafrollers per unit time than bunch examinations, the abundance of leafrollers on leaves was not an accurate means of predicting the level of bunch infestation at harvest. This was possibly due to the much larger area to be examined. Although shoot examinations for eggs and larvae are the basis for monitoring leafrollers on grapevines in Australia (Baker et al. 1994; Shanks et al. 2000), this method is not recommended in New Zealand. Leafroller populations are much higher in Australia, which presumably explains why the technique is successful there.

The main leafroller species on all four vineyards was LBAM. In the pipfruit Integrated Fruit Production programme LBAM are monitored by pheromone traps because fruit damage is correlated with trap catches (Bradley et al. 1998). This study did not find a practical measure of trap catch that could be used as a predictor of bunch infestation at harvest. Catches fluctuated from week to week much more than in pipfruit orchards and seemed to depend largely on the interval between base changes. Vineyards have a more exposed environment than pipfruit orchards and it appeared that bases quickly dried out or became dusty. Changing bases weekly may solve the problem, but this has not been tested. In Australia, pheromone trapping is used to time insecticide applications, but is not reliable for estimating population size (Shanks et al. 2000).

Assessing the incidence of pests and disease at harvest is recommended to measure the success of pesticide programmes. One way to overcome the difficulty in setting a spray threshold during the season is to use the level of bunch infestation at harvest to decide whether a spray was required the following spring. Such a threshold should take into account whether or not a leafroller insecticide had been used during the season.

\section{CONCLUSIONS}

None of the three monitoring methods could be fully recommended for monitoring leafrollers in vineyards. Infestations on leaves and pheromone trap catches were insufficiently well correlated with bunch infestations at harvest to be useful monitoring tools. Examining bunches came closest to fulfilling the criteria needed for a good method, but was only accurate from January onwards which is too late to apply some insecticides. Further work should examine the feasibility of a threshold based on infestations at harvest for making a control decision the following spring.

\section{ACKNOWLEDGEMENTS}

We thank Maurice Menneer, Montana Wines, Te Mata Estate and Villa Maria Estate for giving us access to their vineyards and for collecting pheromone trap data. Vanessa Murrell and Stephen Bradley provided technical assistance. Cathy McKenna and Travis Glare reviewed the manuscript. The research was funded by New Zealand Winegrowers and the Foundation for Research, Science and Technology (Contract no. CO6X0301). 


\section{REFERENCES}

Bailey PT, Ferguson KL, McMahon R, Wicks TJ 1997. Transmission of Botrytis cinerea by lightbrown apple moth larvae on grapes. Australian Journal of Grape and Wine Research 3: 90-94.

Baker GJ, Bailey PT, Charles JG 1994. Leaf and fruit pests: Lightbrown apple moth. In: Nicholas PR, Magarey PA, Wachtel MF ed. Diseases and Pests. Grape Production Series, no. 1. Winetitles, Adelaide, Australia. Pp 47-50.

Bradley SJ, Walker JTS, Wearing CH, Shaw PW, Hodson AJ 1998. The use of pheromone traps for leafroller action thresholds in pipfruit. Proceedings of the 51st New Zealand Plant Protection Conference: 173-178.

Buchanan GA 1977. The seasonal abundance and control of lightbrown apple moth, Epiphyas postvittana (Walker) (Lepidoptera: Tortricidae), on grapevines in Victoria. Australian Journal of Agricultural Research 28: 125-132.

Charles JG ed. 2005. Sustainable Winegrowing New Zealand Vineyard Technical Manual. New Zealand Winegrowers.

Lo PL, Murrell VC 2000. Time of leafroller infestation and effect on yield in grapes. New Zealand Plant Protection 53: 173178.

Shanks A, Braybrook D, Aitkin A 2000. IPM viticulture: Research to practice. Training Workshop Manual. Cooperative Research Centre for Viticulture, Victoria, Australia. 